\title{
Dipeptidylpeptidase-4 (DPP-4) inhibitors are favourable to glucagon-like peptide-1 (GLP-1) receptor agonists: Yes
}

\author{
André J. Scheen \\ Division of Diabetes, Nutrition and Metabolic Disorders, University of Liège, Liège, Belgium \\ Division of Clinical Pharmacology, University of Liège, Liège, Belgium \\ Department of Medicine, CHU Sart Tilman, Liège, Belgium
}

\begin{abstract}
The pharmacological treatment of type 2 diabetes (T2DM) is becoming increasingly complex, especially since the availability of incretin-based therapies. Compared with other glucose-lowering strategies, these novel drugs offer some advantages such as an absence of weight gain and a negligible risk of hypoglycaemia and, possibly, better cardiovascular and $\beta$-cell protection. The physician has now multiple choices to manage his/her patient after secondary failure of metformin, and the question whether it is preferable to add an oral dipeptidylpeptidase4 (DPP-4) inhibitor (gliptin) or an injectable glucagon-like peptide-1 (GLP-1) receptor agonist will emerge. Obviously, DPP-4 inhibitors offer several advantages compared with GLP-1 receptor agonists, especially regarding easiness of use, tolerance profile and cost. However, because they can only increase endogenous GLP1 concentrations to physiological (rather than pharmacological) levels, they are less potent to improve glucose control, promote weight reduction ("weight neutrality") and reduce blood pressure compared to GLP-1 receptor agonists. Of note, none of the two classes have proven long-term safety and positive impact on diabetic complications yet. The role of DPP-4 inhibitors and GLP-1 receptor agonists in the therapeutic armamentarium of T2DM is rapidly evolving, but their respective potential strengths and weaknesses should be better defined in long-term head-to-head comparative controlled trials. Instead of trying to answer the question whether DPP-4 inhibitors are favourable to GLP-1 receptor agonists (or vice versa), it is probably more clinically relevant to look at which T2DM patient will benefit more from one or the other therapy considering all his/her individual clinical characteristics ("personalized medicine").
\end{abstract}

Keywords : DPP-4 inhibitor ; GLP-1 receptor agonist ; Incretin ; Sitagliptin ; Exenatide ; Liraglutide

\section{Introduction}

Type 2 diabetes mellitus (T2DM) is a complex disease that involves a variety of pathophysiological abnormalities, including a defect in incretin hormones [1,2]. Incretins are gut-derived peptides [i.e. glucagon-like peptide-1 (GLP-1) and glucose-dependent insulinotro-pic polypeptide (GIP)] with a variety of glucoregulatory functions. GLP-1 controls elevated blood glucose by triggering pancreatic insulin secretion and suppressing pancreatic glucagon secretion (both in a glucose-dependent manner, therefore not exposing T2DM patients to hypoglycaemia). Furthermore, GLP-1 exerts anorectic activity due to dual effects of slowing gastric emptying and increasing satiety via a central action. T2DM patients exhibit a reduced incretin activity, which can contribute to both basal and postprandial hyperglycaemia [1,2]. Incretin dysfunction can be treated with GLP-1 receptor agonists (e.g., exenatide and liraglutide) or inhibitors of dipeptidyl peptidase 4 (DPP-4) (e.g., sitagliptin, vildagliptin, saxagliptin, alogliptin, linagliptin), the enzyme that degrades GLP-1 into inactive products [2-4]. GLP-1 receptor agonists and DPP-4 inhibitors both elevate GLP-1 activity, the first ones in a pharmacological manner and the second ones in a more physiological manner, and both substantially improve glycaemic control without inducing hypoglycaemia [2]. Extensive reviews have been published recently regarding GLP-1 receptor agonists [5,6] and DPP-4 inhibitors [7,8], which essentially summarize results of randomized clinical trials (RCTs). Both pharmacological classes are increasingly used in the management of T2DM either as monotherapy or more often in combination therapy (mainly with metformin) [9], and we can expect a dynamic development within this field in the coming years [10].

Thus, one important question that may arise is which one of the two classes of incretin-based therapies is the most favourable one for the management of T2DM [11 ]. As the question is posed in this invited debate paper proposed by the Editor, one may hypothesize that DPP-4 inhibitors may be considered favourable to GLP-1 
receptor agonists, which is probably not a general opinion. Personally, 1 would have inverted the locution and formulated the question as follows: "Are GLP-1 receptor agonists favourable to DPP-4 inhibitors: No". Indeed, GLP-1 receptor agonists, but not DPP-4 inhibitors, are recommended as a tier 2 alternative in the algorithm of the so-called ADA (American Diabetes Association)-EASD (European Association for the Study of Diabetes) consensus statement [12], which may suggest that GLP-1 receptor agonists are more favourable than DPP-4 inhibitors for the management of T2DM according to this panel of experts. Although this ADA-EASD position statement has been debated [13], most clinicians indeed are convinced that GLP-1 receptor agonists are more potent than DPP-4 inhibitors, regarding glycated haemoglobin (HbA1c) and body weight reductions (a superiority that is almost demonstrated) and also possibly regarding $\beta$-cell and cardiovascular protection (effects that remain, however, purely speculative). It should be pointed out, however, that "more potent" does not necessarily mean "more favourable", and the debate should be broadened from a clinical point of view, considering not only efficacy but also integrating tolerance, long-term safety, easiness of use, and cost. Furthermore, as briefly discussed at the end of the paper, one may ask whether this question is a good one because of the well-known heterogeneity of T2DM and the increasing recommendation to tailor therapy to the characteristics of each individual T2DM patient, which imposes to have an as large as possible variety of pharmacological means with complementary characteristics.

\section{Comparison using an evidence-based approach}

\section{1. indirect comparisons}

The GLP-1 receptor agonists are more effective in lowering blood glucose and result in substantial weight loss, whereas DPP-4 inhibitors lower blood glucose levels to a lesser degree and are weight neutral. Indirect comparison of the two pharmacological approaches reported in meta-analyses of RCTs of DPP-4 inhibitors, on the one hand, and GLP-1 receptor agonists, on the other hand, confirmed such clinical differences between the two incretin-based approaches [14]. Meta-regression of RCTs of the incretin-based therapy versus placebo showed unadjusted $\mathrm{HbA} 1 \mathrm{c}$ reductions averaging $-0.67 \%$ (95\% confidence interval or $\mathrm{Cl}, 0.52,0.83$ ) for vildagliptin and $-0.79 \%(0.65,0.93)$ for sitagliptin versus $-0.75 \%(0.67,0.83)$ for exenatide and $-1.03 \%(0.90$, 1.16) for liraglutide. A similar approach concerning weight changes demonstrated a slight increase of $+0.56 \mathrm{~kg}$ $(0.27,0.84)$ for vildagliptin and $+0.60 \mathrm{~kg}(0.33,0.87)$ for sitagliptin contrasting with a modest reduction of -1.10 $\mathrm{kg}(-0.88,-1.32)$ for exenatide and $-0.82 \mathrm{~kg}(+0.27,-1.92)$ for liraglutide. One major potential pitfall of this meta-analysis is that data were not adjusted so that confounding factors may interfere with the efficacy results. Some effects beyond glucose control have also been considered when comparing the two pharmacological classes, especially regarding their potential antiatherogenic properties $[15,16]$ and potential benefits (yet untested) in the prevention/treatment of cardiovascular disease [17]. However, only head-to-head trials would allow a perfect comparison between the two types of incretin-based therapies.

\subsection{Head-to-head trials comparing DPP-4 inhibitors versus GLP-i receptor agonists}

Scarce head-to-head comparisons of the two therapies are available yet and only one DPP-4 inhibitor (sitagliptin) has been evaluated in such studies. Two trials compared sitagliptin $100 \mathrm{mg}$ versus exenatide injection either twice daily [18] or once weekly [19] and one trial compared sitagliptin $100 \mathrm{mg}$ with liraglutide injection once daily [20].

In a trial comparing short-term 2 -week treatment with exenatide ( $5 \mu \mathrm{g}$ twice daily for $1 \mathrm{week}$, then $10 \mu \mathrm{g}$ twice daily for 1 week) versus sitagliptin $100 \mathrm{mg}$ once daily, the results were better after treatment with exenatide, as measured by several variables: lowering postprandial glucose, increasing insulin levels, decreasing glucagon levels, and decreasing caloric intake (this trial was too short for assessing HbAlc changes) [18]. These differences were expected considering that exenatide injection is mimicking rather high pharmacological GLP-1 activity whereas DPP-4 inhibition with sitagliptin results in only physiological elevations of endogenous GLP-1 levels. It is quite surprising that no longer trial is currently available that directly compares the classical exenatide form administered twice daily with a DPP-4 inhibitor. A 26-week randomized, double-blind, doubledummy, superiority trial assessed the safety and efficacy of exenatide $2 \mathrm{mg}$ once weekly (not available in clinical practice yet) versus sitagliptin $100 \mathrm{mg}$ once daily in patients treated with metformin. Treatment with exenatide reduced $\mathrm{HbA} 1 \mathrm{c}$ significantly more than did sitagliptin, with a greater weight loss and with no episodes of major hypoglycaemia (Table 1). In addition, reduction in systolic blood pressure (BP) was greater with exenatide twice daily than with sitagliptin (difference of $4 \mathrm{mmHg}$ ), without significant difference in diastolic BP. Both exenatide and sitagliptin were associated with a significant similar increase in HDL cholesterol, but no other significant changes were observed in lipid profile. Similarly, no differences were observed between the two treatment options regarding several other cardiovascular markers. However, exenatide was associated with more 
gastrointestinal adverse events than sitagliptin (nausea: $24 \%$ versus 10\%; vomiting: 11 versus 2\%) [19]. An extension of this study showed that patients who switched to once-weekly exenatide from daily sitagliptin had improved or sustained glycaemic control $(-0.3 \% \mathrm{HbA} 1 \mathrm{c})$, with modest weight loss $(-1.1 \mathrm{~kg})$ and a slight, although significant, reduction in systolic BP $(-2.7 \mathrm{mmHg}, \mathrm{p}<0.05)$, but not in diastolic BP $(-0.4 \mathrm{mmHg})$ [21]. They maintained the HDL cholesterol improvement observed during the initial 26-week treatment (without further improvement) and experienced a modest but significant reduction in total cholesterol $(-0.26 \mathrm{mmol} / \mathrm{l}, \mathrm{p}<$ 0.05 ) without significant changes in LDL cholesterol and triglycerides levels. No significant changes were observed in other cardiovascular markers such as high-sensitivity C-reactive protein, plasminogen activator inhibitor 1 and urinary albumin/creatinine ratio when shifting from sitagliptin to exena-tide once weekly.

In a 24-week prospective trial comparing treatment with liraglutide (1.2 or $1.8 \mathrm{mg}$ once daily) versus sitagliptin $100 \mathrm{mg}$ in metformin-treated patients with T2DM, reductions in HbA1c and body weight were significantly higher with both dosages of liraglutide than sitagliptin (Table 1) [20]. In the liraglutide treatment group, there was an increased incidence of minor side effects such as nausea and vomiting compared with the sitagliptin treatment group (nausea: 21-27 versus 5\%; vomiting: 8-10 versus 4\%). Incidences of hypoglycaemic events were low (5\%) and similar in all treatment groups. These data were confirmed after one year [22]. Estimated mean treatment differences between liraglutide and sitagliptin for HbAlc were $-0.40 \%$ for $1.2 \mathrm{mg}$ and $-0.63 \%$ for 1.8 $\mathrm{mg}$ (both $\mathrm{p}<0.0001$ ), with a 1.5 to $2.5 \mathrm{~kg}$ greater weight loss. Changes in BNP (Brain Natriuretic Peptide) and lipid profile were almost similar in all three treatment arms (Table 1). One case of severe hypoglycaemia with liraglutide $1.2 \mathrm{mg}$, one case of "non-acute" pancreatitis with liraglutide $1.8 \mathrm{mg}$ and one death from a pancreatic carcinoma with liraglutide $1.8 \mathrm{mg}$ were reported in that trial.

Although GLP-1 receptor agonists demonstrate superiority compared to sitagliptin (used as DPP-4 inhibitor of reference), the average differences in $\mathrm{HbAlc}$, weight reduction and BP lowering activity were not impressive compared to several obvious disadvantages of GLP-1 receptor agonists (injectable versus oral, more nausea and vomiting). Further advantages might be expected from GLP-1 receptor agonists, but remain to be demonstrated such as a better cardiovascular protection or a longer durability of glucose control $[3,4]$.

\section{What is recommended in the guidelines?}

As any novel glucose-lowering compound, incretin-based therapies will not fully disclose their spectrum of beneficial and adverse activity before long-term trials with clinical endpoints are available. Nevertheless, several authors tried to describe the current state-of-the-art of using DPP-4 inhibitors or GLP-1 receptor agonists in clinical practice, including an attempt to suggest their place in treatment algorithms for T2DM patients.

The recommendations, as set by the ADA-EASD [12] and the American Association of Clinical Endocrinologists (AACE)/American College of Endocrinology (ACE) [23], recommend starting metformin in most patients on diagnosis of T2DM, but differ in terms of which agents are preferred as second-line therapies. The ADA-EASD so-called "consensus statement" recommended a tiered approach to treatment, starting with well-validated second-line agents, such as sulfonylureas and basal insulin for patients unable to achieve target glucose levels with metformin alone. The higher cost of DPP-4 inhibitors, coupled with an absence of long-term safety and clinical outcome data, was the reason why DPP-4 inhibitors were not selected in this algorithm. However, this position was criticized because it does not offer physicians and patients the appropriate selection of options to individualize and optimise care [13] and a new updated version is currently in preparation. The AACE/ACE recommendations [23], as well as the updated UK NICE (National Institute for Health and Clinical Excellence) guidelines [24], propose a broader range of first- and second-line therapies and combinations, including DPP-4 inhibitors because of their low risk of hypoglycaemia and weight neutrality. An "HbA1c and ABCD" strategy of glycaemia management in T2DM has been published to guide clinicians in the use of therapeutic agents more effectively, efficiently and safely [25]. Accordingly, physicians have to select the therapeutic approach with minimum risk and maximum benefit for each individual, and DPP-4 inhibitors should play an increasing role in such a strategy because of their attractive efficacy/safety balance. 
Table 1 Head-to-head trials comparing a DPP-4 inhibitor and a GLP-1 receptor agonist in T2DM patients already treated with metformin (= or $>1500$ mg/day).

\begin{tabular}{|c|c|c|c|c|c|c|c|c|c|c|c|c|c|}
\hline Reference & $\begin{array}{c}\text { Duration } \\
\text { (wks) }\end{array}$ & Intervention (mg/day) ${ }^{(a)}$ & $\mathrm{n}$ & $\begin{array}{c}\text { Baseline } \\
\text { HbAlc } \\
(\%)\end{array}$ & $\begin{array}{c}\Delta \\
\mathrm{HbA} 1 \mathrm{c} \\
(\%)\end{array}$ & $\begin{array}{c}\text { HbAlc } \\
<7 \% \\
(\% \text { pts })\end{array}$ & $\begin{array}{c}\text { FPG } \\
(\mathrm{mmol} / \mathrm{l})\end{array}$ & $\begin{array}{c}\Delta \\
\text { BW } \\
(\mathrm{kg})\end{array}$ & $\begin{array}{c}\mathrm{SBP} / \mathrm{DBP} \\
\mathrm{mmHg}\end{array}$ & $\begin{array}{l}\mathrm{HR} \\
\mathrm{bpm}\end{array}$ & $\begin{array}{l}\text { LDL-C } \\
\mathrm{mmol} / 1\end{array}$ & $\begin{array}{l}\text { HDL-C } \\
\mathrm{mmol} / 1\end{array}$ & $\begin{array}{c}\mathrm{Tg} \\
\mathrm{mmol} / 1\end{array}$ \\
\hline \multirow{2}{*}{$\begin{array}{l}\text { DeFronzo et al. } \\
\text { (2008) [18] }\end{array}$} & \multirow[t]{2}{*}{2} & Sitaglipti & $61^{(b)}$ & 8.5 & NA & NA & $-0.83^{(\mathrm{c})}$ & -0.3 & NA & NA & NA & NA & $\mathrm{NA}^{(\mathrm{d})}$ \\
\hline & & Exenatide $2 \times 5 \mu \mathrm{g} \rightarrow$ & $61^{(b)}$ & 8.5 & NA & NA & -1.06 & -0.8 & NA & NA & NA & NA & NA \\
\hline \multirow{2}{*}{$\begin{array}{l}\text { Bergenstal et al. } \\
\text { (2010) [19] }\end{array}$} & \multirow[t]{2}{*}{26} & Sitagliptin 100 & 166 & 8.5 & -0.9 & 30 & -0.9 & -0.8 & $+0.3 / \mathrm{NA}$ & NA & +0.04 & +0.05 & -0.10 \\
\hline & & Exenatide $2 \mathrm{mg}$ & 160 & 8.6 & -1.5 & 59 & -1.8 & -2.3 & $-3.7 / \mathrm{NA}$ & NA & -0.03 & +0.05 & -0.10 \\
\hline $\begin{array}{l}\text { Wysham et al. } \\
\text { (2011) [21] }\end{array}$ & 52 & $\begin{array}{l}\text { Shift from sitagliptin } \\
\text { to exenatide (26-52 wks) }\end{array}$ & 116 & 7.5 & -0.31 & +17 & -0.7 & -1.1 & $-2.7 /-0.4$ & NA & -0.09 & -0.01 & +0.03 \\
\hline \multirow[t]{2}{*}{ (2010) [20] } & \multirow{5}{*}{52} & Liraglutide 1.2 & 225 & 8. & -1.24 & 44 & -1.87 & -2.86 & $-0.55 /-0.71$ & +2.32 & +0.08 & 0 & -0.19 \\
\hline & & Liraglut & 221 & 8.4 & -1.50 & 55 & -2.14 & -3.38 & $-0.72 /+0.07$ & +3.94 & +0.05 & 0 & -0.43 \\
\hline \multirow{3}{*}{$\begin{array}{l}\text { Pratley et al. } \\
\text { (2011) [22] }\end{array}$} & & Sitagliptin 100 & 151 & 8.5 & -0.88 & 27 & NA & -1.16 & $-1.03 /-1.47$ & +0.09 & +0.17 & +0.01 & -0.23 \\
\hline & & Liraglutide 1.2 & 135 & 8.4 & -1.29 & 50 & NA & -2.78 & $-0.37 /-0.53$ & +1.72 & +0.09 & +0.01 & -0.10 \\
\hline & & Liraglutide 1.8 & 150 & 8.4 & -1.51 & 63 & NA & -3.68 & $-2.55 /-0.87$ & +3.09 & +0.09 & +0.02 & -0.32 \\
\hline
\end{tabular}

$\Delta$ : change versus baseline. NA: not available. FPG: fasting plasma glucose. BW: body weight. SBP: systolic blood pressure. DBP: diastolic blood pressure. HR: heart rate. LDL-C: LDL cholesterol. HDL-C: HDL cholesterol. Tg: triglycerides.

(a) Except for exenatide.

(b) Cross-over short-term trial.

(c) $2 \mathrm{~h}$-postprandial glucose also available: significantly lower with exenatide compared to sitagliptin $(7.39 \mathrm{mmol} / 1$ versus $11.56 \mathrm{mmol} / 1, \mathrm{p}<0.0001)$.

(d) Postprandial triglycerides also available: reduction with both incretin-based therapies but $10 \%$ greater reduction with exenatide $(\mathrm{p}=0.0118)$. 


\section{Which criteria to be considered to decide which one is better?}

\subsection{Efficacy}

As already mentioned, GLP-1 receptor agonists are slightly more potent to reduce HbA1c levels and body weight than DPP-4 inhibitors. Indirect comparisons of meta-analyses showed a $0.3 \%$ difference in HbA1c and a less than $2 \mathrm{~kg}$ difference in body weight [14]. Such modest differences were confirmed in head-to-head trials, although the reduction seems slightly greater with the maximum $1.8 \mathrm{mg}$ dose of liraglutide (Table 1). Perhaps the effects of GLP-1 receptor agonists on glucose improvement would be more sustained than those of DPP-4 inhibitors, because of a greater weight loss and/or a better $\beta$-cell preservation. However, no head-to-head trial comparing the two therapies lasted more than 52 weeks. In a recent study comparing exposure to exenatide 10 $\mu \mathrm{g}$ twice daily to glargine for 3 years in metformin-treated T2DM patients, most of the effect on insulin secretion observed on exenatide treatment seems to have vanished following a 4-week off-drug period [26]. Although the authors concluded that their "findings suggest a beneficial effect on $\beta$-cell health", data obtained after this short wash-out period do not seem to be in favour of a long-term protection of $\beta$ cell by exenatide, confirming previous observations reported after a one-year treatment [27]. Thus, the effect of $\beta$-cell preservation of GLP-1 receptor agonists in humans remains largely hypothetical and needs to be further substantiated [28].

One may also argue about the benefits of GLP-1 receptor agonists beyond glucose control. Indeed, GLP-1 receptor agonists appear to exert more favourable effects on some cardiovascular risk factors as compared to DPP-4 inhibitors, especially on systolic BP [15]. However, head-to-head trials showed only trivial (if any) differences between GLP-1 receptor agonists and DPP-4 inhibitors as far as lipid profile and various other cardiovascular markers were concerned (Table 1). In fact, the most consistent difference concerned changes in heart rate, which was systematically increased (an effect that is usually considered as unfavourable) with exenatide or liraglutide, but not with sitagliptin (Table 1). Furthermore, the demonstration of favourable effects on surrogate cardiovascular endpoints ("cardiovascular risk markers") is not sufficient anymore to attribute a clear superiority to a pharmacological compound, in absence of clinical trials with hard clinical outcomes (major cardiovascular events) [29].

\subsection{Tolerance}

There is no doubt that the tolerance profile of DPP-4 inhibitors is excellent and better than that of GLP-1 receptor agonists. In general, the incidence of adverse events, including gastrointestinal tolerance, was similar to that of placebo in phase 3 clinical trials with DPP-4 inhibitors [11]. Overall the gastrointestinal tolerance of gliptins is better than that reported with metformin, as shown in several head-to-head trials [7,8]. In contrast, nausea and sometimes vomiting are well known adverse effects of exenatide twice daily, and to a lesser extent of exenatide once weekly and of liraglutide once daily. As already mentioned, these differences were confirmed in head-to-head trials comparing sitagliptin with exenatide once weekly [19] or with liraglutide 1.2 and $1.8 \mathrm{mg}$ once daily [20]. Although these digestive adverse events tended to decrease with time, some T2DM patients have to be withdrawn from clinical trials because of such side effects and this attrition might be even more pronounced in real life clinical practice. Local subcutaneous reactions have also been reported after injection of GLP-1 receptor agonists. Of note, however, despite these possible digestive and local adverse effects and for unknown reasons, the patient's satisfaction evaluated using the Diabetes Treatment Satisfaction Questionnaire improved slightly more with exenatide once weekly than with sitagliptin [19] and with liraglu-tide 1.8 mg once daily than with sitagliptin [20].

\subsection{Safety}

The safety of both incretin-based therapies appears rather good, at least when looking at the short-term exposition data (up to 2 years for available data in clinical trials). However, some concern has been raised with the two types of compounds, mainly an increased risk of pancreatitis and possibly of pancreatic cancer reported with exenatide and sitagliptin (the first-in-class compound) [30]. Fortunately, the concern of increased incidence of C-cell hyperplasia and medullary thyroid cancer with liraglutide reported in rodents has never been confirmed in humans [31] and no increase in calcitonin levels was reported in clinical trials up to 2 years [32]. However, the long-term consequences of liraglutide on calcitonin levels are a subject of further studies. It should be pointed out that no long-term safety data are available with any of incretin-based therapies and that there are no obvious data yet suggesting that one pharmacological class may raise more safety concern than the other. Serious adverse events in clinical trials were too rare to draw any conclusion [22]. The development of antibodies is common with exenatide, but they do not appear to be associated with safety problems (although some reduction in clinical efficacy has been suspected). 


\subsection{Convenience}

DPP-4 inhibitors are very easy to take, as all of them are given as one tablet per day (except vildagliptin, which is better administered as twice daily). Furthermore, there is no need of titration when initiating pharmacological treatment. Finally, as metformin is still considered as the bottom line therapy in T2DM, fixed-dose gliptinmetformin combinations are already available, which should increase both easiness of use and drug compliance [33]. In contrast, therapy with GLP-1 receptor agonists is more complicated because these agents are injectable so that appropriate education from the medical doctor (or from a teaching nurse) is needed. In addition, both exenatide and liraglutide require initial titration in order to improve gastrointestinal tolerance. Even if no difference in perceived convenience of treatment (oral versus injection) was recorded between liraglutide and sitagliptin in one head-to-head study, it should be pointed out that this result was obtained in a trial using an open-label (rather than a double-dummy) design [20]. Presumably, long-lasting GLP-1 receptor agonists in current development may solve, at least partially, patient's reluctance regarding subcutaneous injections.

\subsection{Cost}

The cost of the therapy should also be taken into account in a global comparison for clinical use. Newer incretinbased therapies offer more options for glycaemic control in T2DM. However, they may confer substantial costs to health care systems as shown in a health-economic analysis carried out to better understand the value of adding exenatide and sitagliptin as second-line therapy to glycaemic control strategies for patients with newonset diabetes [34]. DPP-4 inhibitors are less expensive than GLP-1 receptor agonists, although the difference between the two approaches may vary from country to country and may depend on the dose of liraglutide used (1.2 versus $1.8 \mathrm{mg}$ once daily) and possibly on the mode of administration of exenatide (twice daily versus once weekly). Very few studies compared the cost-effectiveness of GLP-1 receptor agonists and DPP-4 inhibitors [35]. Compared with glyburide (glibenclamide), exenatide was associated with greater incremental costeffectiveness ratio per QALY (quality-adjusted life year) compared to sitagliptin as second-line treatment in adult diabetic patients in the US [36]. However, the debate remains open. Compared with the use of sitagliptin, exenatide was associated with lower total medical costs despite higher total diabetes-related costs, suggesting overall cost savings associated with the use of exenatide relative to sitagliptin [37]. However, such indirect comparisons are questionable because of the possible interference of numerous confounding factors.

\subsection{Clinical outcomes}

Neither GLP-1 receptor agonists nor DPP-4 inhibitors have demonstrated a positive effect on microangiopathic complications in patients with T2DM yet. Pooled analyses of phase III clinical trials have shown a trend to a reduction in the incidence of cardiovascular events with each of all five DPP-4 inhibitors (sitagliptin, vildagliptin, saxa-gliptin, alogliptin, and linagliptin), which became significant in pooled analysis [7,38]. In a recently updated meta-analysis of 53 trials, DPP-4 inhibitors were associated with a reduced risk of major cardiovascular events $(\mathrm{OR}=0.689 ; 0.528,0.899 ; \mathrm{p}=0.006)$ compared with placebo or other active treatments [39]. Despite positive cardiovascular effects reported with exenatide or liraglutide [16,40], a similar metaanalysis of 36 trials with exenatide and liraglutide showed a similar trend for a reduction in the incidence of major cardiovascular adverse events, although the difference was not significant versus placebo or active comparators $(\mathrm{OR}=0.74 ; 0.50,1.08 ; \mathrm{p}=0.12)$ [41]. Thus, current data do not support a superiority of GLP-1 receptor agonists over DPP-4 inhibitors regarding potential cardiovascular protection. The protective effects may be attributed to the positive effects of GLP-1 per se, for instance on the endothelial function (and if so, GLP-1 receptor agonists should be more effective because of much higher circulating levels). However, it is also plausible that some of the positive effects are independent of GLP-1 and if so DPP-4 inhibitors that may exert various additional effects might appear more favourable [42]. Only ongoing prospective clinical trials specifically designed to study the effects of cardiovascular events will provide further information in this respect $[7,8]$. However, only indirect comparisons would be possible because none of these ongoing trials is comparing a GLP-1 receptor agonist with a DPP-4 inhibitor.

\section{Which incretin-based therapy is the most favourable? Is it really a good question?}

T2DM is a heterogeneous disease which is evolving with time [1]. The heterogeneity concerns not only molecular defects and pathophysiology (various defects in insulin secretion and insulin sensitivity, for instance), but also other important clinical parameters, including psychological, educational and social aspects. Therefore, it is probably unrealistic to believe that one therapy would be better than the other in all types of T2DM patients. This heterogeneity and the increasing variety of pharmacological tools provide a great opportunity for personalizing treatment strategies according to individual patient characteristics [25]. For instance, DPP-4 
inhibitors may be better suited for early intervention in T2DM management (as initial pharmacological treatment or in combination with metformin), whereas GLP-1 receptor agonists may occupy a privileged position later in the disease, for instance after failure of dual or triple oral therapies as alternative to insulin (or even in combination with insulin, although this is not an official indication yet). Thus, whether one pharmacological approach is more favourable than another one (GLP-1 receptor agonist versus DPP-4 inhibitor as considered here or the reverse) would probably depend on the pathophysiological and other clinical characteristics of each individual patient. It is anticipated that strategies for individualized treatment decisions will emerge with expanding knowledge of polygenic factors and other molecular determinants of disease [43].

\section{Conclusion}

The pharmacological treatment of T2DM becomes increasingly complex and diverse, especially since the commercialization on incretin-based therapies. GLP-1 receptor agonists and DPP-4 inhibitors share several favourable characteristics such as a clinically relevant glucose-lowering effect without inducing hypoglycaemia and without weight gain, which compare positively with other antidiabetic agents. GLP-1 receptor agonists exert a more potent glucose-lowering effect and induce some weight loss and systolic BP reduction compared to DPP4 inhibitors. In contrast, their use is more complex (subcutaneous injection and initial titration), and they are associated with a higher incidence of gastrointestinal adverse events. Only long-term trials with hard clinical outcomes would allow the demonstration of a clear superiority of one pharmacological class over another, but results of such trials are not available yet (and direct comparison trials would not be available in a near future). To my opinion, both types of therapies have a place in the management of T2DM, considering the individual profile of the patient, so that the question of whether DPP-4 inhibitors may be more favourable than GLP-1 receptor agonists (or vice versa) is probably a useless question from a practical clinical point of view.

\section{Learning points}

- Both dipeptidyl peptidase-4 (DPP-4) inhibitors and GLP-1 (glucagon-like peptide-1 ) receptor agonists are incretin-based therapies, which exert clinically relevant glucose-lowering effects. In addition, they offer significant advantages over most classical antidiabetic agents, especially the absence of hypoglycaemia, no weight gain (or even weight loss), improvement in $\beta$-cell function and possibly some protection against cardiovascular complications.

- DPP-4 inhibitors are slightly less potent concerning HbA1c and weight reduction as compared with GLP-1 receptor agonists, but are easier to administer (one single tablet per day), have a better tolerance profile (almost similar to placebo) and are less expensive.

- GLP-1 receptor agonists induced greater reductions in glycaemic indices (fasting and postprandial glucose, HbA1c), body weight and blood pressure compared to DPP-4 inhibitors, but require a subcutaneous injection, are more expansive and may be associated with digestive adverse events, local subcutaneous reactions and formation of antibodies.

- Thus, both DPP-4 inhibitors and GLP-1 receptor agonists have advantages and disadvantages. Thus, instead of positioning these two pharmacological classes in competition, it would be more profitable, from a clinical point of view, to help physicians in selecting the right patient with type 2 diabetes who will benefit the best from one or the other therapy.

- Further long-term studies, if possible with head-to-head comparisons and clinical outcomes, and epidemiological observations of large database (post-marketing surveillance and analysis of registries) would probably be necessary to more carefully delineate the real potential advantages in terms of efficacy/safety ratio and cost-effectiveness between DPP-4 inhibitors and GLP-1 receptor agonists.

\section{Funding and conflict of interest}

No sources of funding were used to assist in the preparation of the manuscript. No conflicts of interest are directly relevant to the content of the manuscript.

AJ. Scheen has received lecture/advisor fees from AstraZeneca/ BMS, Eli Lilly, GlaxoSmithKline, Merck Sharp \& Dohme, Novartis, NovoNordisk, Sanofi-Aventis, Servier and Takeda. 
Published in : European Journal of Internal Medicine (2012), vol. 23, pp. 126-131.

Status : Postprint (Author's version)

\section{References}

[1] De Fronzo RA Banting lecture. From the triumvirate to the ominous octet: a new paradigm for the treatment of type 2 diabetes mellitus. Diabetes 2009;58:773-95

[2] Drucker DJ, Nauck MA. The incretin system: glucagon-like peptide-1 receptor agonists and dipeptidyl peptidase-4 inhibitors in type 2 diabetes. Lancet 2006;368: 1696-705.

[3] Gallwitz B. GLP-1 agonists and dipeptidyl-peptidase IV inhibitors. Handb Exp Pharmacol 2011;203:53-74.

[4] Neumiller JJ. Differential chemistry (structure), mechanism of action, and pharmacology of GLP-1 receptor agonists and DPP-4 inhibitors. J Am Pharm Assoc 2009;49:S16-29.

[5] Charbonnel B, Cariou B. Pharmacological management of type 2 diabetes: the potential of incretin-based therapies. Diabetes Obes Metab 2011;13:99-117.

[6] Gallwitz B. Glucagon-like peptide-1 analogues for type 2 diabetes mellitus: current and emerging agents. Drugs 2011; 71:1675-88.

[7] Scheen AJ. A review of gliptins for 2011. Exp Opin Pharmacotherapy in press.

[8] Scheen AJ. DPP-4 inhibitors in the management of type 2 diabetes : a critical review of head-to-head trials. Diabetes Metab in press.

[9] Davidson JA Incorporating incretin-based therapies into clinical practice: differences between glucagon-like peptide 1 receptor agonists and dipeptidyl peptidase 4 inhibitors. Mayo Clin Proc 2010;85:S27-37.

[10] Ahren B. The future of incretin-based therapy: novel avenues-novel targets. Diabetes Obes Metab 2011;13:158-66.

[11] Campbell RK. Clarifying the role of incretin-based therapies in the treatment of type 2 diabetes mellitus. Clin Ther 2011;33:511-27.

[12] Nathan DM, Buse JB, Davidson MB, Ferrannini E, Holman RR, Sherwin R, et al. Medical management of hyperglycaemia in type 2 diabetes mellitus: a consensus algorithm for the initiation and adjustment of therapy: a consensus statement from the American Diabetes Association and the European Association for the Study of Diabetes. Diabetologia 2009;52:17-30.

[13] Schernthaner G, Barnett AH, Betteridge DJ, Carmena R, Ceriello A Charbonnel B, et al. Is the ADA/EASD algorithm for the management of type 2 diabetes (January 2009) based on evidence or opinion? A critical analysis. Diabetologia 2010;53: 1258-69.

[14] Fakhoury WK, Lereun C, Wright D. A meta-analysis of placebo-controlled clinical trials assessing the efficacy and safety of incretinbased medications in patients with type 2 diabetes. Pharmacology 2010;86:44-57.

[15] Rizzo M, Rizvi AA Spinas GA Rini GB, Berneis K. Glucose lowering and antiatherogenic effects of incretin-based therapies: GLP-1 analogues and DPP-4-inhibitors. Expert Opin Investig Drugs 2009;18:1495-503.

[16] Verges B, Bonnard C, Renard E. Beyond glucose lowering: glucagon-like peptide-1 receptor agonists, body weight and the cardiovascular system. Diabetes Metab 2011 AUG 24 [Epub ahead of print].

[17] Addison D, Aguilar D. Diabetes and cardiovascular disease: the potential benefit of incretin-based therapies. Curr Atheroscler Rep $2011 ; 13: 115-22$

[18] DeFronzo RA, Okerson T, Viswanathan P, Guan X, Holcombe JH, MacConell L. Effects of exenatide versus sitagliptin on postprandial glucose, insulin and glucagon secretion, gastric emptying, and caloric intake: a randomized, cross-over study. Curr Med Res Opin 2008;24:2943-52.

[19] Bergenstal RM, Wysham C, Macconell L, Malloy J, Walsh B, Yan P, et al. Efficacy and safety of exenatide once weekly versus sitagliptin or pioglitazone as an adjunct to metformin for treatment of type 2 diabetes (DURATION-2): a randomised trial. Lancet 2010;376:431-9.

[20] Pratley RE, Nauck M, Bailey T, Montanya E, Cuddihy R, Filetti S, et al. Liraglutide versus sitagliptin for patients with type 2 diabetes who did not have adequate glycaemic control with metformin: a 26-week, randomised, parallel-group, open-label trial. Lancet $2010 ; 375: 1447-56$

[21] Wysham C, Bergenstal R Malloy J, Yan P, Walsh B, Malone J, et al. DURATION-2: efficacy and safety of switching from maximum daily sitagliptin or pioglitazone to once-weeldy exenatide. Diabet Med $2011 ; 28: 705-14$.

[22] Pratley R Nauck M, Bailey T, Montanya E, Cuddihy R Filetti S, et al. One year of liraglutide treatment offers sustained and more effective glycaemic control and weight reduction compared with sitagliptin, both in combination with metformin, in patients with type 2 diabetes: a randomised, parallel-group, open-label trial. Int J Clin Pract 2011;65:397-407. 
[23] Rodbard HW, Jellinger PS, Davidson JA Einhorn D, Garber AJ, Grunberger G, et al. Statement by an American Association of Clinical Endocrinologists/American College of Endocrinology consensus panel on type 2 diabetes mellitus: an algorithm for glycemic control. Endocr Pract 2009;15:540-59.

[24] Adler Al, Shaw EJ, Stokes T, Ruiz F. Newer agents for blood glucose control in type 2 diabetes: summary of NICE guidance. BMJ 2009;338:bl668.

[25] Pozzilli P, Leslie RD, Chan J, De Fronzo R, Monnier L, Raz I, et al. The AIC and ABCD of glycaemia management in type 2 diabetes: a physician's personalized approach. Diabetes Metab Res Rev 2010;26:239-44.

[26] Bunck MC, Corner A Eliasson B, Heine RJ, Shaginian RM, Taskinen MR, et al. Effects of exenatide on measures of \{beta $\}$-cell function after 3 years in metformin-treated patients with type 2 diabetes. Diabetes Care $2011 ; 34: 2041-7$.

[27] Bunck MC, Diamant M, Corner A, Eliasson B, Malloy JL, Shaginian RM, et al. One-year treatment with exenatide improves beta-cell function, compared with insulin glar-gine, in metformin-treated type 2 diabetic patients: a randomized, controlled trial. Diabetes Care 2009;32:762-8

[28] Wajchenberg BL. Clinical approaches to preserve beta-cell function in diabetes. Adv Exp Med Biol 2010;654:515-35.

[29] Goldfine AB. Assessing the cardiovascular safety of diabetes therapies. N Engl J Med 2008;359:1092-5.

[30] Elashoff M, Matveyenko AV, Gier B, Elashoff R, Butler PC. Pancreatitis, pancreatic, and thyroid cancer with glucagon-like peptide-1 based therapies. Gastroenterology 2011;141:150-6.

[31] Parks M, Rosebraugh C. Weighing risks and benefits of liraglutide - the FDA's review of a new antidiabetic therapy. N Engl J Med 2010;362:774-7.

[32] Hegedus L, Moses AC, Zdravkovic M, Le Thi T, Daniels GH. GLP-1 and calcitonin concentration in humans: lack of evidence of calcitonin release from sequential screening in over 5000 subjects with type 2 diabetes or nondiabetic obese subjects treated with the human GLP-1 analog, liraglutide. J Clin Endocrinol Metab 2011;96:853-60.

[33] Scheen AJ. Pharmacokinetic and pharmacodynamic evaluation of sitagliptin plus metformin. Expert Opin Drug Metab Toxicol 2010;6:1265-76.

[34] Sinha A, Rajan M, Hoerger T, Pogach L Costs and consequences associated with newer medications for glycémie control in type 2 diabetes. Diabetes Care 2010;33: 695-700.

[35] Waugh N, Cummins E, Royle P, Clar C, Marien M, Richter B, et al. Newer agents for blood glucose control in type 2 diabetes: systematic review and economic evaluation. Health Technol Assess 2010;14:1-248.

[36] Davis WA Cost-effectiveness analysis: compared with glyburide, sitagliptin associated with incremental cost-effectiveness ratio of $\$ 169,572$ per QALY and exenatide with \$278,935 per QALY as second-line treatment in adult diabetics in the USA Evid Based Med 2010;15:40-1.

[37] Lage MJ, Fabunmi R, Boye KS, Misurski DA Comparison of costs among patients with type 2 diabetes treated with exenatide or sitagliptin therapy. Adv Ther 2009;26:217-29.

[38] Monami M, Iacomelli I, Marchionni N, Mannucci E. Dipeptydil peptidase-4 inhibitors in type 2 diabetes: a meta-analysis of randomized clinical trials. Nutr Metab Cardiovasc Dis 2010;20:224-35.

[39] Lamanna C, Monami M, Bartoli N, Zannoni S, Mannucci E. Dipeptidyl peptidase-4 inhibitors and cardiovascular events: a prospective effect? Diabetologia 2011;54: S109.

[40] Davidson MH. Cardiovascular effects of glucagonlike peptide-1 agonists. Am J Cardiol 2011;108:33B-41B.

[41] Monami M, Cremasco F, Lamanna C, Colombi C, Desideri CM, Iacomelli I, et al. Glucagon-like peptide-1 receptor agonists and cardiovascular events: a metaanalysis of randomized clinical trials. Exp Diabetes Res 2011;2011:215764.

[42] Fadini GP, Avogaro A Cardiovascular effects of DPP-4 inhibition: beyond GLP-1. Vascul Pharmacol 2011;55:10-6.

[43] Malandrino N, Smith RJ. Personalized medicine in diabetes. Clin Chem 2011;57: 231-40. 